\title{
The Role of Transformational Leadership on Employee Performance: A Perspective of Employee Empowerment
}

\author{
Chacha Magasi
}

\section{ABSTRACT}

Critical literature review revealed that individualised consideration and intellectual stimulation factors of transformational leadership are the heart of employee empowerment. This study is important because there was little and discrete information on how individualised consideration and intellectual stimulation empower the performance of banking sector employees in the Dar es Salaam city. The study, therefore, examined the role of transformational leadership on employee performance based on employee empowerment perspective. A sample of 325 banking sector employees was surveyed using a self-administered structured questionnaire. Multiple linear regressions were employed to find the relationship between individualised consideration and intellectual stimulation with the performance of banking sector employees. A Statistical Package for Social Sciences was employed as an analytical tool for quantitative data. An in-depth interview was conducted to twelve employees who were selected by using the purposive sampling technique from twelve different banks. Thematic analysis was used to analyse qualitative data from in-depth interview to supplement the quantitative findings. The study revealed that individualised consideration and intellectual stimulation had a positive relationship with the performance of banking sector employees. That relationship was enhanced by effectively empowering employees and also fostering an environment that encourages learning, creativity and innovation. The study recommends that leaders in any bank's section have to empower employees and foster the learning, creativity and innovation environment as the preconditions for enhanced employees' performance. However, the study was done in the Dar es Salaam city and therefore limiting the generalisation of the results due to contextual differences in sub-Saharan countries. The study contributes to knowledge that individualised consideration and intellectual stimulation factors of transformational leadership are the heart of employee empowerment.

Keywords: Banking sector, employee performance, individualised consideration, intellectual stimulation, role of transformational leadership.
Submitted : October 10, 2021

Published : November 10, 2021

ISSN: 2507-1076

DOI : $10.24018 /$ ejbmr.2021.6.6.1137

Chacha Magasi

Marketing Department, College of Business Education, Dodoma, Tanzania.

(e-mail: magasitza@ ${ }^{\circledR}$ mail.com)

*Corresponding Author

\section{INTRODUCTION}

The banking sector has been crucially boosting the global economy more than ever since it stabilises financial systems, facilitates funds flow and ensures efficient financial resources allocation. The banking sector creates job opportunities, is the medium for value transactions, advances loans to investors, generates tax revenues, invests in high-grade securities, and improves the country's GDP (Anyango, 2015; BOT, 2018). Banks are the main financial institutions in Tanzania and facilitate economic development, growth, and stabilisation (IMF, 2016). The banking sector has been mushrooming all over the world and it operates in a dynamic, complex, and rapidly changing business environment than ever before (Abouraia \& Othman, 2017; ADB, 2016). Speedy globalisation, ever-changing technologies, scarce resources, stiff competition, and exposure to social media make the business environment in which the banking sector operates even much more difficult (Abb \& Miller, 2016;
Suriyankietkaew \& Avery, 2016). Under such circumstances, suitable leadership styles are needed to adapt to quick globalisation, stiff competition, consumer behavioural diversity and pressures from shareholders and stakeholders. The banking sector should, therefore, be committed to sustaining sound, healthy and stable businesses through suitable leadership styles as a strategy for avoiding the manageable financial crisis and its severe consequences.

In order to excel in a complex, competitive and dynamic environment, the banking sector is not only required to empower employees in terms of knowledge, skills, experience and attitude but also fosters creativity and innovation environment work environment as a way of achieving superior performance and sustained competitive advantage (Belias \& Koustelios, 2014; Mwita, Mwakasangula, \& Tefurukwa, 2018; Northouse, 2016; Yukl, 2013). The right and strong leadership style is fundamental for ensuring bank's productivity, change management, transformation, and value creation (Gathaiya, 2017; George, 
2003; Mohammed, Chowdhury, \& Sanju, 2017). Value creation indicators include the presence of modern and stable technologies, cost leadership strategy, several business portfolios, new and attractive products, markets innovation, risk management strategies, green sales, stable value chains and reputable management (Abb \& Miller, 2016).

Effective and efficient creation, implementation, standardisation and sustenance of value-added activities and operations make the banking sector more creative, innovative, competitive and improving in performance. Leadership is also a key factor in shaping corporate behaviours and motivating and encouraging others to promote new strategies for organisational development and positive changes (Manaf \& Latif, 2014). Leadership is important in shaping corporate behaviours, acquiring culture dynamics, empowering individuals, creating teamwork and improving individual skills (Manaf \& Latif, 2014; Taruwinga, 2011). Strong and quality leadership is possible if the bank has competent staff who strategically think much ahead, evaluate ideas and decide wisely before doing. However, leadership becomes useless if the leader's decisions and actions are directed towards improving employees' strengths through training, coaching, mentorship, building teamwork, a conducive working environment and fostering creativity and an innovation (Jackson, 2016; Tan, 2009). The best leaders always map and evaluate the speed of industry growth, strengths and weaknesses of competitors, available business opportunities, existing technology, existing capital, and human resource strengths.

Senior leaders become the source of job underperformance in some banks in Sub-Saharan countries such as Tanzania because of incompetence and failure to empower employees and foster diverse thinking and innovation (BOT, 2018; Ugoani, Amu, \& Emenike, 2014). Some banks have been closed in Tanzania because of non-performing and noncompliance with regulatory requirements, partly caused by a lack of leadership and management competencies (BOT, 2018). Some organisation's leaders are poor not only in empowering employees but also unable to create a creativity and innovation supportive climate (Northouse, 2016). Likewise, leaders fail to equip employees with the essential leadership competencies and skills and, consequently, individual employee performance is also severely affected (Bass \& Avolio, 1994). These kinds of leaders are likely to have poor plans for long-term strategy, inability to develop competent human assets, inability to harvest and use expertise, failure to add value to the organisation and are usually weak to managing change.

Employee empowerment is possible if management capitalises on individualised consideration and intellectual stimulation that are important than ever to motivate employees' capability growth and creativity enhancement (Mohammed, Chowdhury, \& Sanju, 2017). However, there is little information on how individualised consideration and intellectual stimulation relate to employee performance in the banking sector in the Dar Salaam city. Besides, there is a lack of literature to support the validity of Bass and Avolio's (1995) Multifactor Leadership Questionnaire (MLQ) transformational leadership measurement model in SubSaharan countries such as Tanzania, and hence attracting more studies. The objective of this study was therefore to investigate the role of transformational leadership on employee performance. The concentration of the study was on employee empowerment through the two transformational leadership factors, namely individualised consideration and intellectual stimulation factors. The study contributes to knowledge on the role of transformational leadership on employee empowerment in sub-Saharan countries particularly Tanzania.

\section{LITERATURE REVIEW}

\section{A. Theoretical Review}

The theoretical framework is the basis on which all knowledge is constructed for a research study since it serves as the structure and justification for the study. The study used the transformational leadership theory (Burns, 1978). The theory states that a transformational leader continually influences and transforms the thought of followers by raising their awareness, articulating their vision, and encouraging them to align their self-interest with that of the organisation, as well as empowering them to learn how to achieve the desired group goals and outcomes (Burns, 1978). Transformational leadership is one of the most significant benchmarks in organisation's success since a transformational leader can make followers feel enthusiastic about the success of an organisation (Manaf \& Latif, 2014). Interestingly, (Bass, 1985) advanced transformational leadership into four measurable factors namely idealised influence, inspirational motivation, individualised consideration, and intellectual stimulation. Variables individualised consideration and intellectual stimulation were chosen and examined together because they have close interdependent relationships in contributing to the performance of employees (Groves, 2014; Northouse, 2016).

\section{B. Empirical Review}

This section covers an empirical review on the influence of individualised consideration and intellectual stimulation on employee performance. Individualised consideration encourages teamwork and recognises equality amongst employees and also contributes to positive leadership results and longevity in business firms (Scotland, 2010). Although the aforementioned study explains the importance of individualised consideration, it does not explain how encouraging teamwork and recognising equality contribute to business longevity. Individualised consideration also contributes to positive business survival and success (Akpan, 2017; Westhuizen, 2014). Besides, literature show that all four components of transformational leadership style: idealised influence, inspirational motivation, intellectual stimulation, and individualised consideration, have a positive effect on the predicted outcomes of the subordinates in the developed countries (Jackson, 2016). Despite a good conclusion, the study does not specify under which situation the components of transformational leadership predict the subordinate's outcomes and what those outcomes are. Individualised consideration strongly and positively affects post-acquisition performance (Savovic, 2017). Changing one level of individualised consideration positively changes one level of employee commitment and satisfaction (Malik, Javed, \& Hassan, 2017). Individualised consideration is thus 
unavoidable since it helps to improve the leadership competencies and grooming the next generation of leaders through mentoring and coaching (Ajiboye, 2017). In contrast, individualised consideration has been found to have no significant effect on employee calculative commitment (Waris, Khan, Ismail, Adeleke, \& Panigrahi, 2018). However, since the discussed empirical studies were conducted outside Tanzania and also, they have contradicting findings, there is a need to fill that gap. Based on the literature review and research gaps, this research hypothesises that:

$H_{o 1}$ : There is no significant relationship between individualised consideration and the performance of banking sector employees in the Dar es Salaam city.

Intellectual stimulation involves leadership that arouses the followers much more creative and innovative, and at the same time challenging their status quo as well as those of the leader and the firm (Northouse, 2016). It has been revealed that intellectual stimulation is mostly used for sensitising employees to make decisions and promote innovation and creativity in improving productivity at the workplace (Ajiboye, 2017). Scotland (2010) underlines that the company founder's ability to adapt, innovate, and exploit opportunities, leads to positive business succession results and longevity. Furthermore, assigning challenging work to employees stimulates and promotes their creativity and significantly contributes to their performance and the success of the business (Trang, 2016). Studies indicate that creativity and innovation among employees lead to successful business performance (Gumbo, Ngugi, Gakure, \& Ngugi, 2012). It has also been observed that changing one level of intellectual stimulation leads to a positive effect on employee comment and satisfaction (Malik, Javed, \& Hassan, 2017). Improved employee performance is achieved when a leader encourages employees to think critically in dealing with issues they face at work, use their own initiative, and seek innovative methods to do their work and assignments (Ogola, Linge, Sikalieh, \& Linge, 2017). In contrast, Savovic (2017) argues that intellectual stimulation has the weakest effect on business post-acquisition performance. Likewise, it has been found that intellectual stimulation has no significant relationship with employees' creativity (Suifan \& Al-Janini, 2017) and also no significant impact on employee calculative commitment and performance (Waris, Khan, Ismail, Adeleke, \& Panigrahi, 2018). Due to a lack of harmony and consensus on how intellectual stimulation relates to employee performance, further study is needed to fill existing gaps. Also, many of these studies were conducted in Asia and Europe and therefore difficult to generalise the same findings to Dar es Salaam city of Tanzania in Sub-Saharan African countries. Besides, the past studies do not explain under which climate and work environment can leaders successfully arouse the followers' creativity and innovation. Based on the literature review and research gaps, this research hypothesises that:

$H_{o 2}$ : There is no significant relationship between intellectual stimulation and the performance of banking sector employees in the Dar es Salaam city.
From the theoretical and empirical review, the independent variables are intellectual stimulation and individualised consideration. It is suggested that leaders with intellectual stimulation behaviours empower employees through encouraging creativity, innovation, re-examining assumptions, assigning them challenging works and encouraging them to have problem-solving alternatives. Besides, it is mentioned that leaders with individualised consideration behaviours empower employees through power delegation, building teamwork and developing their strengths, capabilities, and competencies. Moreover, literature shows that indicators of employee performance in the banking sectors are quality and reliable products, quality and reliable financial services, quality and reliable markets, quality and reliable technology, many product portfolio and effective feedback. The study, therefore, used these constructs and their respective indicators to test their relationship with a dependent variable.

\section{Conceptual Framework}

The study was guided by the transformational leadership theory which focuses on moving and changing things in a big way, by communicating to followers a special vision of the future (Northouse, 2016). The conceptual framework in figure I was built from the theoretical and empirical literature review under part II (section A and B). The assumption was that individualised consideration and intellectual stimulation influence the performance of the banking sector employees.

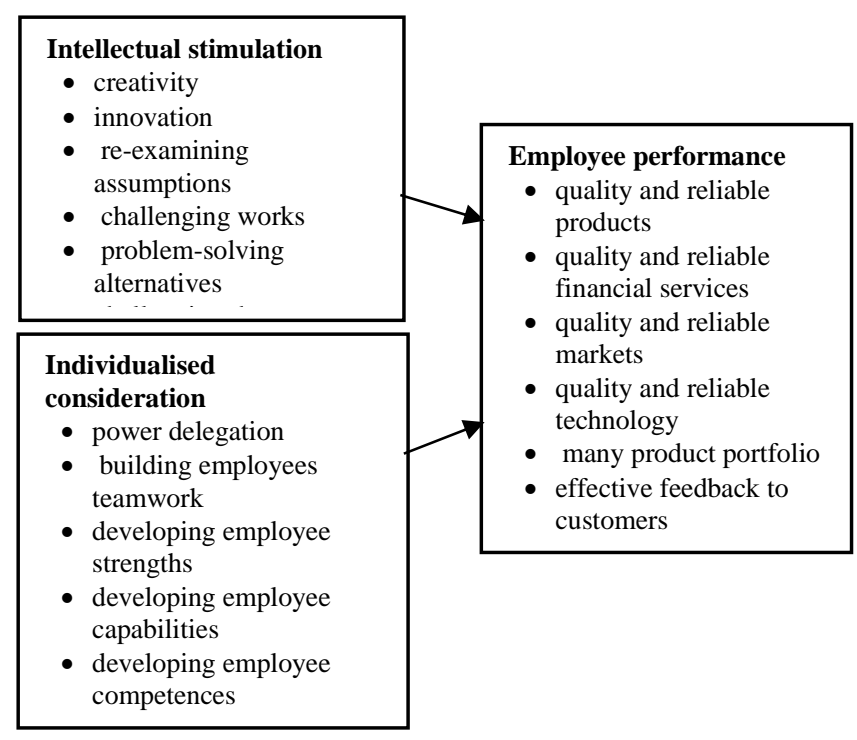

Fig. I: Conceptual framework. Source: Literature.

\section{RESEARCH METHODS}

The study used the positivism paradigm since positivists believe in the possibility of establishing a cause-effect relationship by using deduction approach to test hypotheses (Creswell, 2014). The study investigated the relationship between the predicators, namely individualised consideration and intellectual stimulation, and a dependent variable, namely employee performance. This research adopted a correlational research design that aims to determine relationship between the predicators and independent variable (Creswell, 2014). The study utilised survey research as it gives a quantitative or 
numeric description of attitudes or opinions of a population by using the selected sample (Kothari, 2009). A crosssectional survey design was utilised as it allows data to be collected at one point of time using structured instruments (Kothari, 2009). The study area was Dar es Salaam city because of leading in having many banks in Tanzania (NBS, 2016). And also, (BOT, 2018) reports that some of them were severely underperforming. The units of observation were employees of banks located in Dar es Salaam city since their performance was to some extent being affected by the existing leadership styles (BOT, 2018).

The study adopted the Green's (1991) formula for calculating the sample size, which is represented by the equation $\mathrm{N}>50+8 \mathrm{~m}$, where $\mathrm{N}=$ sample size; and $\mathrm{m}=$ number of independent variables. Since the study had two independent variables, based on the formula, the required sample size should be greater than 66. However, (Anders \& Zhou, 2017) used a sample of 155 instead of 82 minimum sample size based on the 4 predictor variables and was almost twice the minimum sample size. Therefore, the study used a sample of 131 instead of 66 based on 2 predictor variables. A simple random sampling technique was used to choose a sample to prevent bias, as each bank had a chance of being selected (Kothari, 2009; Saunders, Lewis, \& Thornhill, 2012). The independent variables (individualised consideration and intellectual stimulation) were measured relying on the basis of the improved version of Bass and Avolio's (1995) MLQ model. All two measures of the independent variables and the dependent variable used the 5points Likert scale survey where $1=$ strongly Disagree, and 5 = strongly Agree. The study used a structured questionnaire for the collection of primary data. The questionnaire was similar for all banks and with closed-ended questions and a 5-points Likert scale to ensure precision and consistency. The researcher and assistants visited the targeted banks to distribute the structured questionnaires for filling in by the respondents via a self-administered approach.

The Cronbach's alpha value $(\alpha)$ was utilised to verify if the measurements were reliable based on an alpha value $\geq 0.70$ (Hair, Black, Babin, \& Anderson, 2010). In order to ensure the content validity, the concepts of all variables were systematically covered in the measurement instruments (Creswell, 2014). Principal Component Analysis (PCA) was used to evaluate if the construct validity was achieved. Multiple regression analysis was applied as a data analysis technique to test the hypotheses based on the equation (1):

$\mathrm{Y}=\beta_{0+} \beta_{1} \mathrm{IC}+{ }_{+} \beta_{2} \mathrm{IS}+\varepsilon$

where $\mathrm{Y}$ is the predicted value of dependent variable employee performance and $\beta_{0}$ is the $\mathrm{Y}$-intercept (constant) in regression; $\beta_{1}$ is the estimated regression coefficient of Individualised consideration (IC) denoting the net change in $\mathrm{Y}$ for each unit change in the predicator IC holding predicator IS and $\beta_{2}$ is the estimated regression coefficient of intellectual stimulation (IS) denoting the net change in Y for each unit change in the predicator IS holding predicator IS fixed. Finally, $\varepsilon$ is a random variable added to accommodate the effect of other factors that have an influence on employee performance but are not included in the model.
The interpretation of the findings was by examining the calculated $t$ value and judging whether they were significant $(\mathrm{p}<0.05)$ or insignificant $(\mathrm{p}>0.05)$.

To supplement quantitative data, qualitative data were also collected through in-depth interview from twelve interviewees of twelve different banks by using the purposive sampling technique in 20 hours. Purposive sampling was the powerful sampling technique for an in-depth interview since it identified and selected information-rich banking sector employees which could address well the role of transformational leadership in empowering the banking sector employees. The collected qualitative added more information which could not be captured by quantitative data to increase reliability and validity of data since Mashenene (2016) adopted the similar approach. Also, thematic analysis was used to analyse qualitative data collected from twelve banks to examine, categorise, tabulate and recombine evidences to address the research problem. The findings obtained from qualitative data were compared and contrasted with the literature and quantitative findings to enrich more information on the relationship of the variables under study.

\section{RESUlTS}

\section{A. Reliability and Validity Test}

The aim of conducting the reliability analysis was to establish if the data collected could consistently reflect the constructs that were being measured. Table I shows that both Cronbach's alpha values for the independent variables were greater than the minimum value of 0.7 (Saunders et al., 2012) indicating that data were accurate and reliable.

\begin{tabular}{ccc}
\multicolumn{3}{c}{ TABLE I: RELIABILITY RESULTS } \\
\hline $\begin{array}{c}\text { Cronbach's } \\
\text { Alpha }\end{array}$ & N of Items \\
\hline $\begin{array}{c}\text { Individualised } \\
\text { consideration }\end{array}$ & 0.894 & 6 \\
Intellectual stimulation & 0.930 & 7 \\
\hline
\end{tabular}

Source: Field data (2020).

Factor analysis was used to test whether the construct validity for independent variables was met. The KaiserMeyer-Olkin (KMO) which is a measure of sampling adequacy had a value of 0.911 as indicated in Table II. Hence, the KMO value was also greater than the threshold value of 0.5 which implies that the sample was sufficient. In addition, Bartlett's test of sphericity was significant $(p=0.000)$ which supports the successful factorisation of variables.

\begin{tabular}{|c|c|c|}
\hline \multicolumn{2}{|c|}{$\begin{array}{l}\text { Kaiser-Meyer-Olkin Measure of Sampling } \\
\text { Adequacy. }\end{array}$} & 0.911 \\
\hline Bartlett's Test of & Approx. Chi-Square & 1142.959 \\
\hline Sphericity & Df & 78 \\
\hline & Sig. & 0.000 \\
\hline
\end{tabular}

Principal Component Analysis (PCA) was run based on Eigenvalue to find if the construct validity was ensured. Appendix I indicates that the factor analysis of each item loading of the independent variables was greater than the standard minimum value of 0.5 which implies that the construct validity was met. 


\section{B. The Findings for Correlations}

Correlational analysis assesses whether there is a correlation between and among variables without inferring cause and effect of the variables (Hair, Black, Babin, \& Anderson, 2010). Correlational analysis also checks whether there is multicollinearity problem between independent variables.

\begin{tabular}{ccccc}
\multicolumn{5}{c}{ TABLE III: CORRELATIONS ANALYSIS RESULTS } \\
\hline & & IC & IS & EP \\
\hline \multirow{2}{*}{ IC } & Pearson & 1 & & \\
& Correlation & & & \\
IS & Pearson & $0.380^{* *}$ & 1 & \\
& Correlation & $(0.000)$ & 1 & \\
& Pearson & $0.400^{* *}$ & $0.477^{* *}$ & 1 \\
EP & Correlation & $(0.000)$ & $(0.000)$ & \\
& $\mathrm{N}=131$ & & & \\
\hline
\end{tabular}

**. Correlation is significant at the 0.01 level (1-tailed).

Source: Field data (2020).

Table III indicates the correlation between independent variables, namely individualised consideration (IC) and intellectual stimulation (IS), and the dependent variable, namely employee performance (EP). The marks ** indicate statistical significance at the $1 \%$ level. P-values were reported in the respective parenthesis. Data analysis for Pearson correlations indicates that $* * \mathrm{p}<0.01$ correlation was significant at the 0.01 level. Besides, all correlation coefficients derived from the correlation between independent variables ranged from 0.380 to 0.477 (low positive correlation), indicating absence of multicollinearity problems.

\section{Testing Hypotheses}

Testing hypotheses was done to examine the relationships between the independent variables and an independent variable. The results are summarised in Tables IV to VI.

\begin{tabular}{ccccc}
\multicolumn{5}{c}{ TABLE IV: MODEL SUMMARY } \\
\hline Model & $\mathrm{R}$ & R Square & $\begin{array}{c}\text { Adjusted R } \\
\text { Square }\end{array}$ & $\begin{array}{c}\text { Std. Error of } \\
\text { the Estimate }\end{array}$ \\
\hline 1 & $0.743^{\mathrm{a}}$ & 0.712 & 0.507 & 7.71828
\end{tabular}

a. Predictors: (Constant), IC, IS.

Source: Field data (2020).

Table V shows that overall model fit satisfactorily suits the acceptable levels on statistical criteria since the $\mathrm{p}$-value for the regression model is far less than the critical p-value. The implication is that the two independent variables individualised consideration (IC) and intellectual stimulation (IS) in total predict employee performance in the banking sector.

TABLE V: ANOVA F TEST

\begin{tabular}{ccccccc}
\multicolumn{8}{c}{ TABLE V: ANOVA F TEST } \\
\hline \multirow{2}{*}{ Model } & $\begin{array}{c}\text { Sum of } \\
\text { Squares }\end{array}$ & Df & $\begin{array}{c}\text { Mean } \\
\text { Square }\end{array}$ & \multirow{2}{*}{ F } & \multirow{2}{*}{ Sig. } \\
\hline \multirow{2}{*}{1} & Regression & 3014.43 & 2 & 1507.22 & 25.30 & $0.000^{\mathrm{b}}$ \\
& Residual & 7625.20 & 128 & 59.57 & & \\
& Total & 10639.63 & 130 & & & \\
\hline
\end{tabular}

a. Dependent Variable: EP.

b. Predicators: (Constant), IC, IS.

Source: Field data (2020).

Table VI shows the coefficients of multiple linear regression analysis. The standardised coefficients were utilised in building the regression model since they have standardised data that can be explicitly compared, which is comparatively difficult for the unstandardised data (Hair, Black, Babin, \& Anderson, 2010). Multiple linear regressions coefficients were used to construct equation (2).

$\mathrm{Y}=8.615+.256 \mathrm{IC}+.379 \mathrm{IS}+\varepsilon$

The findings in Table 6 and equation (1-2) show a positive $(\beta=0.256)$ and significant $(\mathrm{t}=3.167 ; \mathrm{p}=0.002)$ relationship between the individualised consideration and employee performance. As a result, $\mathrm{H}_{1 \mathrm{a}}$ is supported. Also, the findings in Table VI and equation (1-2) show a positive $(\beta=0.379)$ and significant $(\mathrm{t}=4.691 ; \mathrm{p}=0.000)$ relationship between the idealised influence and employee performance. Thus, $\mathrm{H}_{1 \mathrm{a}}$ is supported.

TABLE VI: MULTIPLE LINEAR REGRESSION COEFFICIENTS

\begin{tabular}{|c|c|c|c|c|c|c|}
\hline & \multirow{2}{*}{ Model } & \multicolumn{2}{|c|}{$\begin{array}{c}\text { Unstandardised } \\
\text { Coefficients }\end{array}$} & \multirow{2}{*}{$\begin{array}{c}\text { Standardised } \\
\text { Coefficients } \\
\text { Beta }\end{array}$} & \multirow{2}{*}{$\mathrm{T}$} & \multirow{2}{*}{ Sig. } \\
\hline & & B & $\begin{array}{c}\text { Std. } \\
\text { Error }\end{array}$ & & & \\
\hline \multirow{3}{*}{1} & (Constant) & 8.615 & 3.036 & & 2.838 & 0.005 \\
\hline & IC & 0.435 & 0.138 & 0.256 & 3.167 & 0.002 \\
\hline & IS & 0.461 & 0.098 & 0.379 & 4.691 & 0.000 \\
\hline
\end{tabular}

a. Dependent Variable: EP.

Source: Field data (2020).

The findings in Table VI and equation (2) show a positive $(\beta=0.256)$ and significant $(p=0.002)$ relationship between the individualised consideration and employee performance. As a result, $\mathrm{H}_{1 \mathrm{a}}$ is supported. Also, the findings in Table VI and equation $(1-2)$ show a positive $(\beta=0.379)$ and significant $(\mathrm{p}=0.000)$ relationship between the idealised influence and employee performance. Thus, $\mathrm{H}_{1 \mathrm{a}}$ is supported.

\section{RESULTS ORIENTED DISCUSSION}

The study focused on investigating the influence of individualised consideration and intellectual stimulation on the performance of banking sector employees in Dar es Salaam city. The study aimed at helping to gain deeper knowledge of how individualised consideration and intellectual stimulation influence the performance of banking sector employees. The findings in Table VI and equation (2) show that individualised consideration had a significant positive influence on the performance of banking sector employees in Dar es Salaam city. These results are contrary to the findings of Waris, Khan, Ismail, Adeleke, and Panigrahi's (2018) that individualised consideration has no significant impact on employee performance and their calculative commitment. However, interviewees argued that lack of individualised consideration can lead to organisation's failure. For example, an interviewee D from bank Q commented that: "....... A supervisor who fails to analyse, identify and give each individual employee the consideration he or she needs such as a supportive working climate, demotivates employees to perform better their duties and responsibilities. If my supervisor doesn't listen and care for me, it will be difficult to be committed to accomplish the assigned tasks and duties. If lack of commitment prevails all over the organisation, then it will be much more difficult to accomplishing the set bank's goals...". Besides, Meyer and Allen (1997) suggest three steps for employee commitment 
to the firm which need the close support of immediate supervisors. These are employee continuance commitment (employee evaluates cost and benefit of leaving the firm), affective commitment (employees affection to remain in the firm), and normative commitment (employees feel a sense of contractual obligation to the team members). As such, if there is a lack of supportive climate to employees, those employees will not be committed to their jobs and organisation. As a result, their performance would also be relatively low and thus lead to the overall underperformance of the organisation. The implication is that employees are committed to working if supervisors closely support them based on individual personal needs. Otherwise, lack of supportive climate and employees' commitment is unfavourable to the bank's performance.

The findings, are, however, consistent with other studies that individualised consideration is an essential factor for employee and organisation's performance (Ajiboye, 2017; Malik, Javed, \& Hassan, 2017; Savovic, 2017; Westhuizen, 2014). Also, during in-depth interview, it was clear that presence of employees' individual consideration motivates them to work hard and enjoy the job. Interviewee $\mathrm{H}$ from bank $\mathrm{U}$ argued that: "I like a leader who personalises his or her leadership and spends time to give each individual the consideration he or she needs on an individual basis... an indication that he or she cares about others. I indeed feel happier because my supervisor often pays close attention to me. Apart from giving me a supportive working climate, he mentors, trains and encourages me how to solve complicated work problems". Therefore, it is wise to conclude that individualised consideration contributes to positive leadership outcomes, employee performance, bank performance and business sustainability.

The findings in Table VI and equation (2) show that intellectual stimulation had a significant positive influence on the performance of banking sector employees in Dar es Salaam city. However, these findings are contrary to existing empirical studies (Savovic, 2017; Suifan \& Al-Janini, 2017; Waris, Khan, Ismail, Adeleke, \& Panigrahi, 2018). Intellectual stimulation has no significant relationship with employees' creativity, performance and calculative commitment to work (Suifan \& Al-Janini, 2017; Savovic, 2017). Besides, intellectual stimulation has the weakest impact on business post-acquisition performance and outcomes (Savovic, 2017). Yet, the findings from the aforementioned studies do not disclose why intellectual stimulation has no relationship with employee performance. In-depth interviews revealed that some supervisors hesitate to provide an environment that fosters intellectual stimulation because of either a fear to be criticised or failure of untested attempts. Interviewee J from bank $\mathrm{W}$ commented: “...The biggest problem of my immediate supervisor is the total discouragement of we employees to question assumptions, status quo and routine ways of doing things. Challenging the existing status quo means insubordination to him and therefore liable to receive a severe punishment. We, therefore, always do the job in favour of his interests to avoid being punished...." Basing on that argument, the supervisor kills creativity and independent thinking among employees. Discouraging employees to challenge the assumptions, status quo, routine ways of doing things makes them fear to solve complicated problems on their own. Under that circumstances, employees' creative thinking to try tackling things in new ways and learning from mistakes is disheartened. As a result, change management will be weak in that particular bank. There is no doubt that in today's digital economy and innovation era, competition of knowledge is not a major factor in winning the market. Allowing new ideas, creativity, imagination, independent thinking and translating own ideas into products and reality are the cornerstone to superior performance, winning the competition and sustainability of the banking sector. Empirical studies emphasise that intellectual stimulation promotes critical thinking and creativity, contributes to employees' performance and also organisation's performance (Gumbo, Ngugi, Gakure, \& Ngugi, 2012; Ogola, Linge, Sikalieh, \& Linge, 2017; Trang, 2016).

Likewise, if one level of intellectual stimulation is changed, it would lead to a more positive influence on employee commitment and satisfaction (Malik, Javed, \& Hassan, 2017). Moreover, the findings from in-depth interview strongly support that intellectual stimulation is important in enhancing employee's performance in the banking sector. Similarly, interviewee A from bank $M$ commented: ...always competent supervisors encourage employees to try new approaches and ways in solving the prevailing problems. My supervisor is a hero since she allows us to look at and try things from different angles as a strategy of coming up with novel and useful ideas. She further encourages us to change those ideas into products and services.... In this way, our bank shines in providing services and products to our esteemed customers....". Moreover, existing studies are in favour of respondent's A argument. Intellectual stimulation is associated with assigning challenging works to employees to stimulate and promote their creativity and innovation (Trang, 2016). Intellectual stimulation arouses subordinates much more creative, innovative, and challenging individual, management and organisation status quo. It also sensitises employees to make decisions, promotes creativity and innovation to significantly improve productivity at the workplace (Northouse, 2016). Also, interviewee D from bank Q argued that: ...I always believe that encouraging new thinking, creativity and innovation culture is the brain and heart of every bank if that bank wants to delight its customers. ...I thank much our boss since he always encourages us to challenge routine beliefs, values and ways of tackling issues. This is quite different from my former supervisor in the company where I got employed after graduating from the University. He was always discoursing new ideas and learning through mistakes by fearing that the company could get the loss...." The management has the responsibility of promoting adaptation, creativity, innovation and exploitation of available business opportunities as the strategies for bringing positive changes that contribute to superior business performance and longevity (Scotland, 2010). Thus, it is concluded that leaders with intellectual stimulation behaviours encourages employees' performance as a strategy for effective and superior bank's performance. 


\section{CONCLUSION}

The study investigated the influence of individualised consideration and intellectual stimulation on the performance of the banking sector employees in the Dar es Salaam city of Tanzania. The findings show that individualised consideration and intellectual stimulation have a positive significant influence on the performance of banking sector employees. The study provides a coherent understanding that giving each individual employee the consideration he or she needs through caring, power delegation, building teamwork, and developing his or her strengths, capabilities, and competencies, improves individual employee performance. The study also provides a comprehensive understanding that promoting intellectual stimulation through encouraging independent thinking, creativity, innovation, re-examining critical assumptions, challenging works and status quo and different problem-solving alternatives, improve individual employee performance. Thus, the individualised consideration and intellectual stimulation are crucial for enhancing the performance of banking sector employees.

The study contributes to empirical and theoretical knowledge in the sub-Saharan context and in particular Tanzania where little was known on the influence of individualised consideration and intellectual stimulation on employee performance. Leaders in the banking sector are, therefore, advised to foster an environment which motivates the employees to optimise in individualised consideration and intellectual stimulation practices. Bank supervisors should recognise the employees' needs, desires and motives by supporting them to develop their abilities in order to meet the demands of individuals and firms. Also, bank supervisors should provide the environment that support employers to be creative, innovative and find solutions to challenges and problems by including them in the decisionmaking process, enhancing their efforts, and motivating them to challenge the status quo.

The study had a few limitations which need to be addressed by future studies. The study was conducted in the banking sector which has the white-collar employees, and therefore a bit difficult to generalise the findings. To test the reliability of the findings, the same study can be done in other sectors such as manufacturing, warehousing, and mining businesses, which usually have many blue-collar employees.

\section{APPENDIX}

APPENDIX I: FACTOR ANALYSIS PATTERN MATRIX

\begin{tabular}{clc}
\multicolumn{4}{c}{ APPENDIX I: FACTOR ANALYSIS PATTERN MATRIX } \\
\cline { 2 - 3 } Item & \multicolumn{1}{c}{ Item statement } & \multicolumn{1}{c}{ Component } \\
\hline \multicolumn{4}{c}{ Moderating variable: Individualised consideration } \\
\hline IC1 & $\begin{array}{l}\text { My supervisor helps me to develop my } \\
\text { strengths for both personal and bank } \\
\text { benefits. }\end{array}$ & 0.724 \\
IC2 & $\begin{array}{l}\text { My supervisor facilitates training, } \\
\text { teaching, mentoring, and coaching me. }\end{array}$ & 0.615 \\
IC3 & $\begin{array}{l}\text { My supervisor encourages the team } \\
\text { spirit among employees at our } \\
\text { workplace. } \\
\text { My supervisor encourages me to make } \\
\text { the most use of my skills and } \\
\text { capacities. } \\
\text { My supervisor supports me with the } \\
\text { necessary working tools. }\end{array}$ & 0.771 \\
IC5 0.667
\end{tabular}

\begin{tabular}{|c|c|c|c|}
\hline IC6 & $\begin{array}{l}\text { My supervisor confidently delegates } \\
\text { assignments to me to provide learning } \\
\text { opportunities. }\end{array}$ & 0.601 & \\
\hline \multicolumn{4}{|c|}{ Independent variable: Intellectual stimulation } \\
\hline IS1 & $\begin{array}{l}\text { My supervisor promotes creativity and } \\
\text { innovative spirit among employees and } \\
\text { within the bank. }\end{array}$ & & 0.651 \\
\hline IS2 & $\begin{array}{l}\text { My supervisor encourages me to re- } \\
\text { examine critical assumptions to } \\
\text { question whether they are suitable or } \\
\text { not. }\end{array}$ & & 0.656 \\
\hline IS3 & $\begin{array}{l}\text { My supervisor assigns me with the } \\
\text { challenging works and assignments to } \\
\text { encourage my creativity. }\end{array}$ & & 0.658 \\
\hline IS4 & $\begin{array}{l}\text { My supervisor allows me to seek } \\
\text { different perspectives/alternatives in } \\
\text { problem-solving. }\end{array}$ & & 0.812 \\
\hline IS5 & $\begin{array}{l}\text { My supervisor allows me to think } \\
\text { existing problems in new ways. }\end{array}$ & & 0.742 \\
\hline IS6 & $\begin{array}{l}\text { My supervisor allows me to challenge } \\
\text { the current status quo. }\end{array}$ & & 0.716 \\
\hline IS7 & $\begin{array}{l}\text { My supervisor encourages me to } \\
\text { search and learn from outside the } \\
\text { formal boundaries of the business. }\end{array}$ & & 0.730 \\
\hline
\end{tabular}

\section{REFERENCES}

Abouraia, M., \& Othman, S. (2017). Transformational Leadership, Job Satisfaction, Organizational Commitment, and Turnover Intentions: The Direct Effects among Bank Representatives. American Journal of Industrial and Business Management, 7, 404-423.

ADB. (2016). Country Strategy Paper 2016-2020. African Development Bank.

Ajiboye, O. (2017). Effective Leadership Practices of Bank Leaders in Nigeria. PhD study. Walden University, PhD Study.

Akpan, L. \&. (2017). Succession Planning and Survival of Small Scale Businesses in Benue State. Akpan, L., \& Ukpai, A. (2017). Succ International Journal of Scientific and Research Publications, 7(2), 408-411.

Anders, L. S., \& Zhou, Y. (2017). What Drivers Purchase Intention Towards Ethical Products: A study Using Modified Theory of Planned Behavior. Bachelor's thesis. Linnaeus University Sweden.

Anyango, C. (2015). Effects of Leadership Styles on Employee Performance at Bank of Africa in Kenya Limited. Dar es Salaam: The Open University of Tanzania.

Bass, B. M. (1985). Leadership and performance beyond expectations. New York: The Free Press.

Bass, B., \& Avolio, B. (1994). Transformational leadership and organizational culture. International Journal of Public Administration, 17(3/4), 541-554.

Bass, B., \& Avolio, B. (1995). MLQ Multifactor Leadership Questionnaire, Leader Form, Rater Form, and Scoring. California Palo Alto, CA: Mind Garden.

Belias, D., \& Koustelios, A. (2014). Transformational Leadership and Job Satisfaction in the Banking Sector: A Review. International Review of Management and Marketing, 4(3), 187-200.

BOT. (2018). Bank of Tanzania Annual Report 2017/18. Dodoma: Bank of Tanzania.

Burns, J. (1978). Leadership. New York: Harper \& Row.

Creswell, J. (2014). Research Design: Qualitative, Quantitative and Mixed Methods. (4, Ed.) Los Angels, USA: SAGE.

Gathaiya, R. (2017). Analysis of Issues Affecting Collapsed Banksin Kenya from 2015-2016. International Journal of Management and Business Studies, 7(3), 9-15.

George, B. (2003). Authentic Leadership: Rediscovering the Secrets to Creating Lasting Value. Harvard: Harvard Business Review.

Green, S. B. (1991). How Many Subjects Does it Take to Do a Regression Analysis. Journal of Multivariate Behavioral Research, 23(6), 499510.

Groves, K. S. (2014). Examining leader-follower congruence of social responsibility values in transformational leadership values in transformational leadershipl. Journal of Leadership \& Organizational Studies, 21, 227-243.

Gumbo, C. O., Ngugi, J., Gakure, R., \& Ngugi, P. (2012). Role of Succession Planning on Survival of Small and Medium Family Enterprises after Retirement/death of the First Generation Entrepreneurs in Kenya. International Journal of Business and Social Research (IJBSR), 2(6), $109-124$. 
Hair, J. F., Black, C. W., Babin, B. J., \& Anderson, R.E. (2010). Multivariate Data Analysis (7 ed.). Upper Saddle River, New Jersey: Pearson Education.

IMF. (2016). United Republic of Tanzania: Selected Issues-Microfinancial Issues. Washington, D.C: International Monetary Fund.

Jackson, T. (2016). The Relationship Between Transformational Leadership Style and Employees' Perception of Leadership Success in Higher Education. PhD Study. Liberty University .

Kothari, C. (2009). Research Methodology: Methods \& Techniques (2 ed.). New Delhi: New Age International Publishers.

Malik, W., Javed, M., \& Hassan, S. (2017). Influence of Transformational Leadership Components on Job Satisfaction and Organizational Commitment. Pakistan Journal of Commerce and Social Sciences, 11(1), 147-166.

Manaf, A., \& Latif, A. (2014). Transformational Leadership and Job Performance of SMEs Technical Personnel: The Adaptability Cultural Approach as Mediator. Mediterranean Journal of Social Sciences, $5(20), 648-655$

Meyer, J., \& Allen, N. (1997). Commitment in the workplace: Theory, research, \& application. Thousand Oaks, CA: Sage Publications.

Mohammed, I., Chowdhury, S. R., \& Sanju, N. (2017). Leadership Styles Followed in Banking Industry in Bangladesh: A case Study on Some Selected Banks and Financial Institutions. American Journal of Theoretical and Applied Business, 3(3), 36-42.

Mwita, K., Mwakasangula, E., \& Tefurukwa, O. (2018). The Influence of Leadership on Employee Retention in Tanzania Commercial Banks. International Journal of Human Resource Studies, 8(2), 274-283.

NBS. (2016). Statistical Business Register Report 2014/2015. Dar es Salaam : National Bureau of Statistics .

Northouse, P. G. (2016). Leadership Theory and Practice (7 ed.). Michigan: SAGE Publications, Inc.

Ogola, M., Linge, K., Sikalieh, D., \& Linge, T. (2017). The Influence of Intellectual Stimulation Leadership Behaviour on Employee Performance in SMEs in Kenya. International Journal of Business and Social Science, 8(3), 89-100.

Saunders, M., Lewis, P., \& Thornhill, A. (2012). Research Methods for Business Students (6 ed.). Saffron House, 6-10 Kirby Street, London: Pearson.

Savovic, S. (2017). The impact of the dimensions of transformational leadership on the post-acquisition performance of the acquired company. Economic Horizons, 19(2), 97-109.

Scotland, J. A. (2010). Factors that influence positive succession outcomes and longevity in long-lasting Australian family enterprises. PhD Study. Lismore, NSW: ePublications@SCU, Southern Cross University.

Suifan, T., \& Al-Janini, M. (2017). The Relationship between Transformational Leadership and Employees' Creativity in the Jordanian Banking Sector. International Review of Management and Marketing, 7(2), 284-292.

Suriyankietkaew, S., \& Avery, G. (2016). Sustainable Leadership Practices Driving Financial Performance: Empirical Evidence from Thai SMEs. Sustainability, 8(327), 1-14.

Tan, J. P. (2009). An Investigation of Corporate Leadership Succession Planning and Implementation: The Malaysian Experience. Massey University.

Taruwinga, P. (2011). The Influence of Cultural Factors on Successful succession Plan in Indian South African Family owned Businesses (Based in Indiana). PhD Study. UNISA: SBL.

Trang, H. P. (2016). Library Leadership and Succession Planning in Vietnam. RMIT University.

Ugoani, J. N., Amu, C. U., \& Emenike, K. O. (2014). Poor Management and Failed Banks: A Study of Banks with State Government. International Journal of Economics, Commerce and Management Participation in Nigeria, 2(11), 1-19.

Waris, M., Khan, A., Ismail, I., Adeleke, A. Q., \& Panigrahi, S. (2018). Impact of leadership qualities on employee commitment in multiproject-based organizations. IConCEES 2017 (pp. 1-9). IOP Publishing.

Westhuizen, J. P. (2014). Leadership practices of first and second generation family business owners and the correlation with performance. Vaal Triangle: North-West University.

Yukl, G. (2013). Leadership in organizations (8 ed.). Upper Saddle River, NJ: Pearson Education. 